\title{
Using Virtual Reality and Smart Textiles to Assess the Design of Workstations
}

\author{
Francisco GARCIA RIVERA ${ }^{\mathrm{a}, 1}$, Erik BROLIN ${ }^{\mathrm{a}}$, Anna SYBERFELDT ${ }^{\mathrm{a}}$, Dan \\ HÖGBERG $^{\mathrm{a}}$, Aitor IRIONDO PASCUAL ${ }^{\mathrm{a}}$ and Estela PEREZ LUQUE ${ }^{\mathrm{a}}$ \\ a School of Engineering Science, University of Skövde, Skövde, Sweden
}

\begin{abstract}
This paper presents a solution that integrates a smart textiles system with virtual reality to assess the design of workstations from an ergonomics point of view. By using the system, ergonomists, designers, engineers, and operators, can test design proposals of workstations in an immersive virtual environment while they see their ergonomics evaluation results displayed in real-time.. The system allows its users to evaluate the ergonomics of the workplace in a preproduction phase. The workstation design can be modified, enabling workstation designers to better understand, test and evaluate how to create successful workstation designs, eventually to be used by the operators in production. This approach uses motion capture together with virtual reality and is aimed to complement and integrate with the use of digital human modelling (DHM) software at virtual stages of the production development process.
\end{abstract}

Keywords. Virtual reality, motion capture, ergonomics, simulation

\section{Introduction}

The industry is going towards a new stage called "Industry 4.0" [1], in which digitalization is a major theme. One of the central techniques within Industry 4.0 is simulation, which has become one of the essential tools used in the industry to optimize current situations and predict future ones. The use of simulation is increasing as its reliability and accessibility are improving all the time, along with numerous demonstrations of its efficiency and effectiveness [2]. Various parameters of the product and the associated production can be considered in earlier stages of the product realization process, and along the life-cycle of the product and the production. This enables proactivity, from the product and production conception to the end of the product and production life-cycle, which allows companies and organizations to increase their performance [3].

Acting proactively in the industry involves the necessity of considering as many aspects, scenarios and situations as possible in the early stages of the development process, i.e. proactively solving problems at the design stage, rather than reactively solving them after they occurred. Production aspects are among the most important to be considered, since an efficient production system is essential to stay competitive in the market, and also, many problems can arise if the production is not planned carefully.

\footnotetext{
${ }^{1}$ Corresponding Author. francisco.garcia.rivera@his.se
} 
Workers' wellbeing, which is closely related to the ergonomics of the workspace, is among these production aspects. An ergonomic workstation is essential to provide the operators with a better work situation as well as better life quality [4]. It avoids work-related musculoskeletal disorders (WMSDs) [5] including the problems that it causes to the companies, related to quality [6], productivity [7] and performance [8], as well as to the society, both economically $[9,10]$ and socially [11].

Digitalization and virtual tools included in the concept of Industry 4.0 can be used to assess the ergonomics in the design of workstations. One of the most important among the ergonomics tools available in the market is digital human modelling (DHM) [12]. DHM can be described as human simulation consisting of digital human models, so- called manikins, in a virtual environment. DHM is commonly used to assess and validate the interaction between humans and products or workstations to enrich and improve its design [13], mainly regarding ergonomics. There are several DHM tools available such as Siemens Jack [14], IPS IMMA [15] and Santos [16].

\section{Ergonomics evaluations and virtual reality}

Numerous assessing techniques for ergonomics are available. These techniques are usually classified in three categories: self-report (different types of questionnaires to the workers), observational techniques (ergonomist observing and assessing the performance of the task), and direct measurement methods (which rely on measuring devices, such as motion sensors, attached to the subject) [17]. Direct measurements methods are the most advanced and objective techniques since they rely on numeric data, and the results do not depend on the assessor's judgment. To analyze the data, several observational methods for posture evaluation to identify and assess risk factors in the workplace can be applied. Some of them are Rapid Upper Limb Assessment (RULA) [18], Rapid Entire Body Assessment (REBA) [19], and Ovako Working Posture Assessment System (OWAS) [20] among others.

By using motion capture, ergonomics evaluations can for example be performed by attaching inertial measurement units (IMUs) on a person's body to keep track of his/her movements [21], and then analyzing the data with ergonomics evaluation methods such as RULA, REBA and so on [22]. Such techniques can be applied to assess the design of new workstations in a pre-production phase. A physical prototype of a new workstation can be built to replicate the task that the workers are supposed to execute in the production line. Then, the movements are performed while recording data with IMUs attached to the subject's body. Based on that data the design of the workstation can be iterated to identify successful design solutions.

However, such a process can be time-consuming and expensive, especially building and redesigning physical prototypes. This problem can be reduced by making use of new technologies such as virtual reality (VR).

VR is defined as a group of technologies that aim to immerse the user in an immersive computer-generated environment. It can be used to add value to traditional simulations shown on 2D flat screens [23] or substitute physical prototypes [24]. In the context of workstation design, VR enables designers, engineers, and ergonomists to test their designs with no need for physical prototypes. Therefore, the design process can be more efficient [25] and enriched based on user experience in a virtual environment [26]. 


\section{Proposed system combining virtual reality and motion capture}

This paper presents a solution that combines a motion capture (mocap) based system for direct measurements and ergonomics evaluations, with VR to assess the design of workstations from an ergonomics perspective in a virtual environment. Based on the user's postures, the solution can display real-time ergonomics evaluations in the VR environment. In this way, ergonomists, designers, engineers and operators (here referred to as users) can perform the work tasks in the virtual environment and see how the ergonomics evaluation is for a specific design. With the ergonomics evaluations, and based on the user's experience in VR, the layout of the workstation can be iterated, and improved design solution can be reached.

\subsection{Previous work on combining virtual reality and motion capture}

The idea of combining mocap with VR has become popular in recent years. The core idea is to use VR as a graphical representation of the reality, and mocap as the system to keep track of the posture. The main characteristics of similar systems presented recently are shown in the list below.

- Daria et al. combine ErgoLog to perform ergonomics evaluations, together with a IMU based mocap system connected to Siemens Jack to run the workstation simulation [27].

- Caputo et al. combine a IMU based mocap system developed at the University of Campania Luigi Vanvitelli to track the posture, and EAWS digital by MTM to perform the ergonomics evaluation, all connected to Siemens Tecnomatix to run the virtual environment [28].

- Peruzzini et al. use Delmia V5-6 for workstation digitalization, Vicon Tracker for posture tracking (Optical Motion Capture system), Catia for manikin digitalization, Haption RTI Delmia for connection among real user movements and virtual manikin movements [29].

\subsection{Elements of the developed system}

The main elements of the system presented in this paper consist of a smart textiles system, i.e. an IMU based motion capture equipment together with an ergonomics analyzer, and VR equipment. The smart textiles system is a result of previous research $[30,31,32,33]$. The smart textiles system includes three IMUs, one placed on the trunk and one on each upper arm (Figure 1). The smart textiles system can provide realtime ergonomics feedback based on the data collected by the IMUs (such as joint angles and angular velocity). 

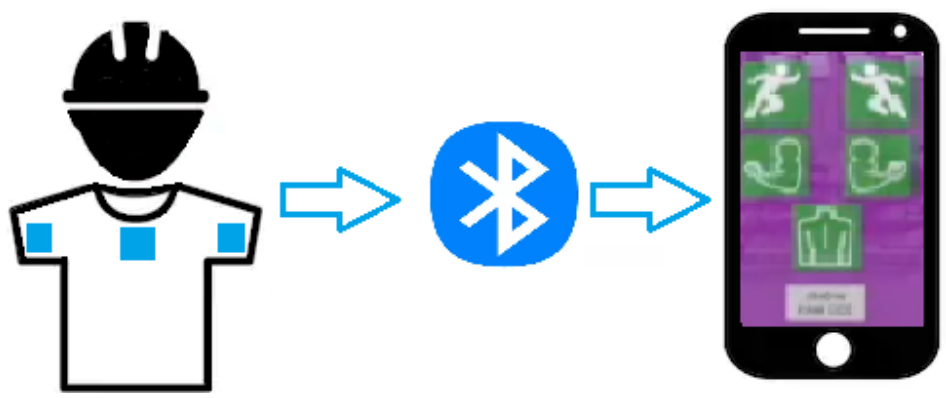

Figure 1. Principal representation of the smart textiles system

The VR equipment used to display the virtual environment is HTC VIVE [34]. It has been validated as a good option to pick-and-place tasks [35]. The equipment consists of a head-mounted display (HMD) with a refresh rate of $90 \mathrm{~Hz}$ and 110-degree field of view, two controllers with multiple inputs such as pad and several buttons, as well as two base stations that emit infrared pulses to track the locations of the HMD and the controllers.

The software used to run the VR immersive environment is IPS [36]. IPS is generally used for virtual verification of assembly feasibility, motion planning and so on. IPS has a VR functionality that is used to show any environment imported or created in the software. IPS supports some interaction between the user and the elements that are in the virtual environment, such as tools and objects. This functionality makes IPS suitable for testing virtual workstations.

The main characteristic of the system developed is that it can show ergonomics evaluation results inside of the VR environment. To do that, a standalone program was developed to collect the ergonomics evaluation results from the smart textiles system and push the data into the VR environment. This program is based on the open-source project OpenVRDesktopPortal, made with the Unity game engine. Its purpose is to overlay a $2 \mathrm{D}$ virtual screen in VR when another program is being displayed [37]. Some features and functionalities were adapted to make it compatible with the smart textiles system.

\subsection{System operation}

The system consists of two different parts that are running in parallel. One part is responsible for displaying the virtual environment and handling interactions between the user and the virtual environment, whereas the other part is controlling the ergonomics evaluations. An overview of the system's data flow is shown in Figure 2. 


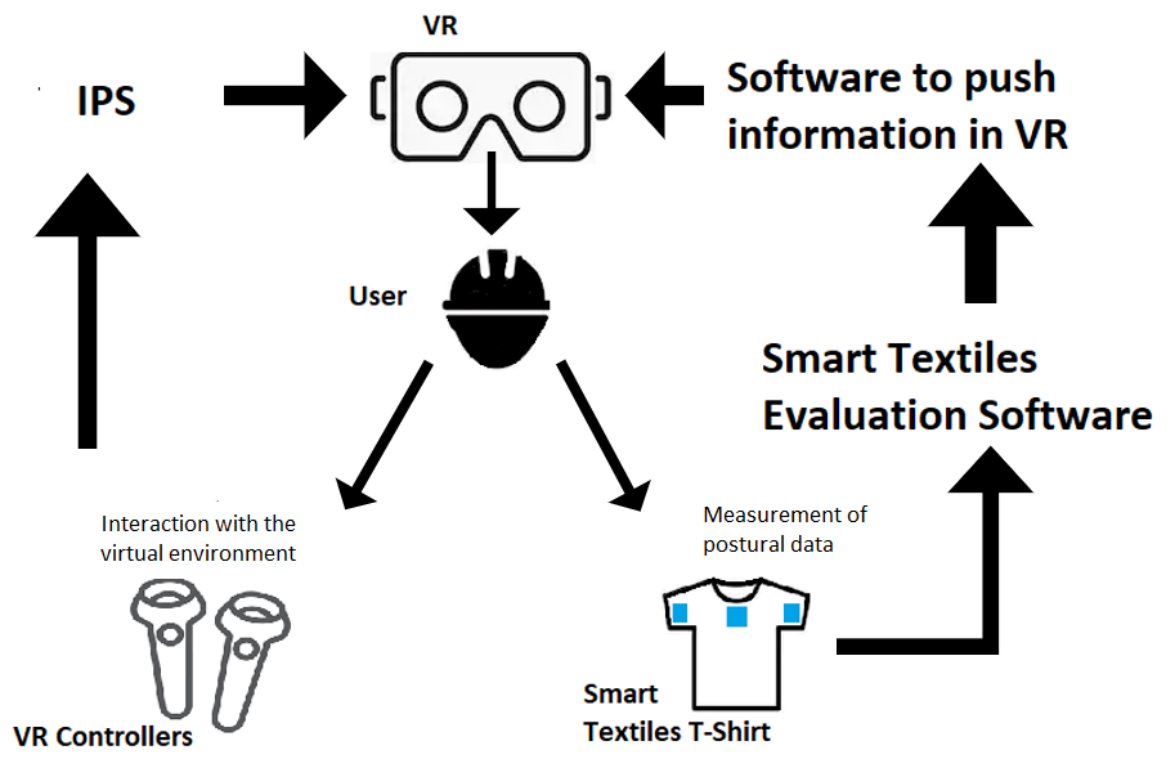

Figure 2. Main components and data flow of the system

As shown in Figure 2, on one side the program in charge of displaying the VR environment is running and displaying the virtual environment as well as handling the user's interactions with it through the VR equipment. On the other side, the user is wearing the motion capture equipment, keeping track of the user's movements and providing the ergonomics evaluations. The ergonomics evaluations are pushed into the virtual environment by a specific software developed for the system. This software captures what the ergonomics evaluation interface is displaying, and then overlays this into the virtual environment, so that the user can see the ergonomics evaluation results in VR.

\section{Results}

To test the system, it was implemented in a case study in which a company wanted to assess the ergonomics impact of implementing a collaborative robot in one of its assembly stations. An example of what the system looks like in the case study from the user's perspective is shown in Figure 3.

The ergonomics feedback is given by visual stimulus. In Figure 3, the different parts of the body (trunk and arms) are colored differently depending on how ergonomic the posture is. There are three colors to illustrate the ergonomics status of the posture. Green color shows that the posture is ergonomically sound, and that it normally can be maintained for long periods. Yellow color represents a posture that should not be maintained long periods, and neither should be repeated a high number of times per day. Red color stands for postures that should be avoided. The specific angles and exposure criteria are based on Arvidsson et al., as well as Lind [38, 39]. 

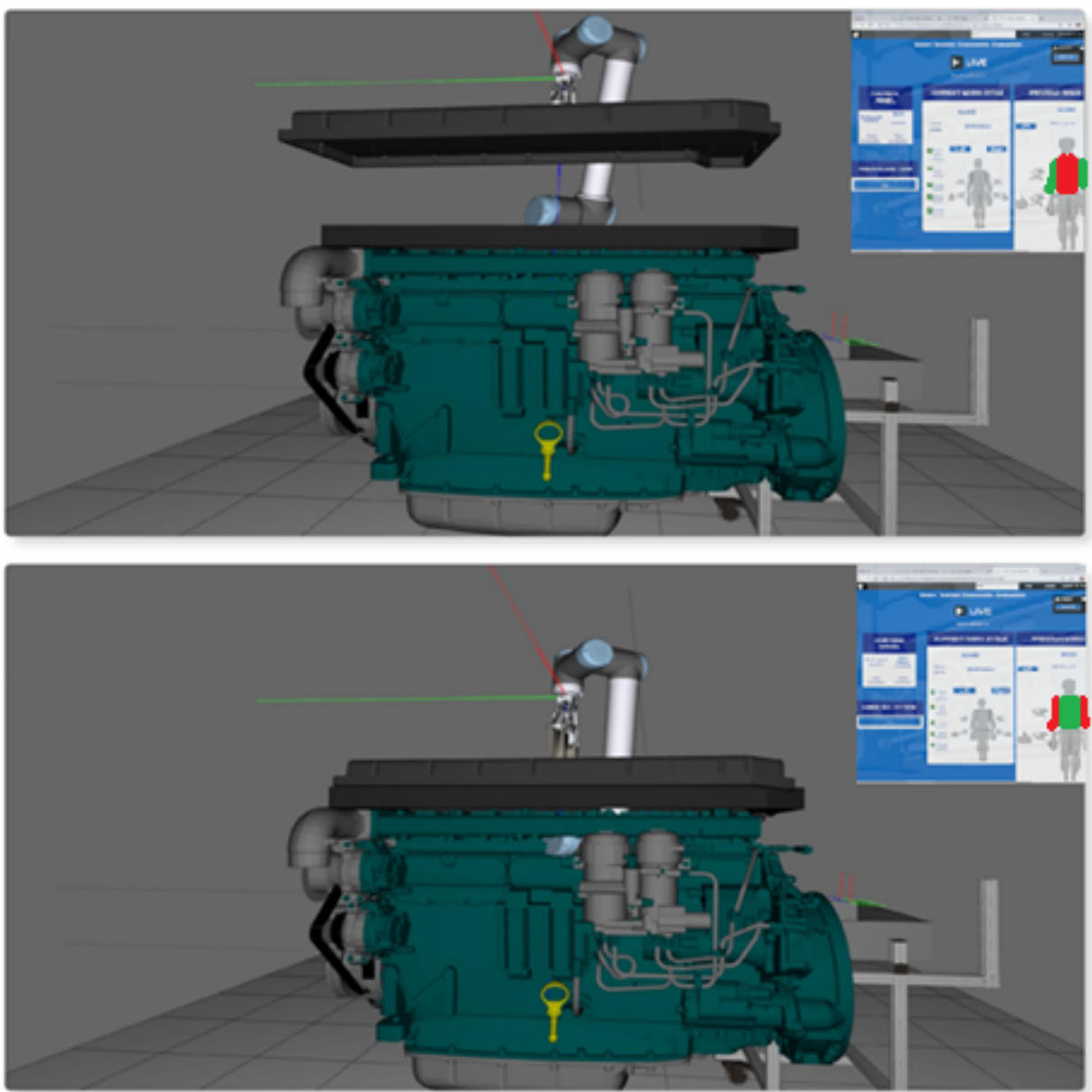

Figure 3. Implementation of ergonomics evaluation feedback in IPS VR

The system can also run together with other VR capable programs. Figure 4 shows the system running together with a different application, where the user is shown on the right side and the user's view in the VR system, and the corresponding ergonomics evaluation, are shown on the left side.

\section{Summary and discussion}

The system presented in this paper gives an immersive experience complemented with the data-based decision-support system for improved ergonomics. This approach can help ergonomists, designers, and engineers etc. to test and improve workstation designs in a cost-effective way, both existing workstations and workstations that have not yet been built. A similar solution could also be used to train operators to perform work tasks in the virtual environment before entering the actual production line, e.g. train workers of how to perform tasks according to instructions, as well as how to perform tasks in an ergonomic manner. 


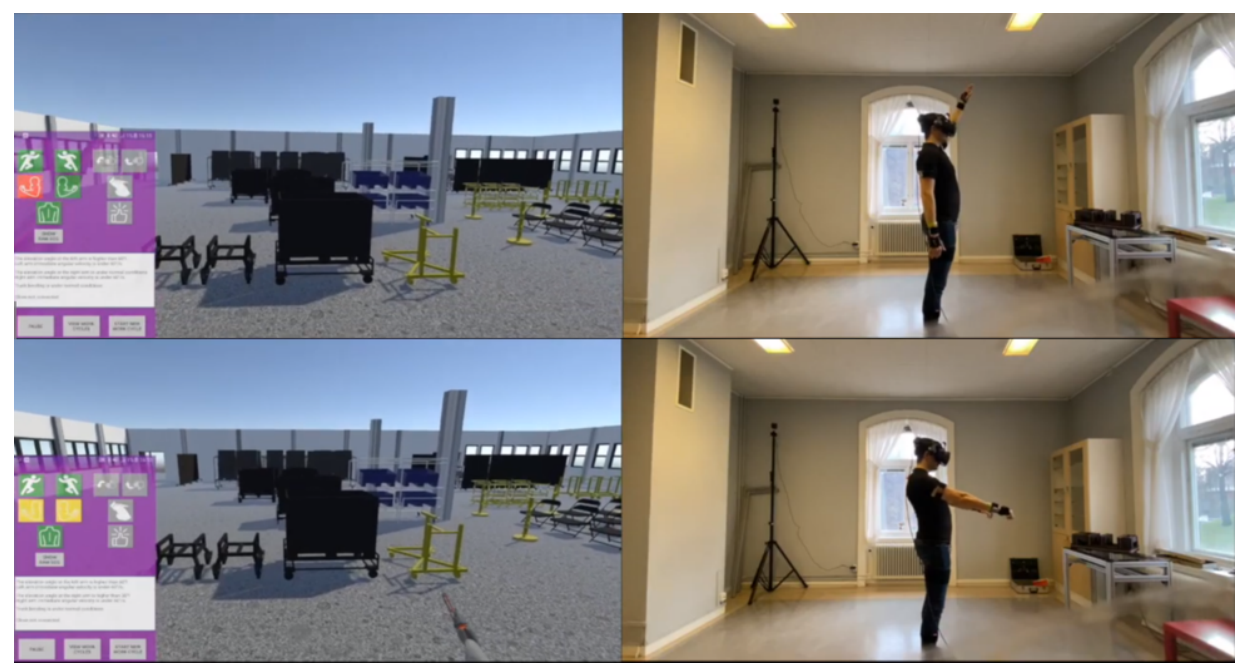

Figure 4. User's view and ergonomics evaluation in VR environment (left), user wearing mocap system and VR equipment (right)

The main limitations of the approach presented in this paper regard current limitations of the VR technology in itself. Some parameters such as the grasping of the tools, weight, collisions with objects cannot yet be simulated. For instance, the developed system cannot be used to study the biomechanical effects of lifting objects or applying forces when performing work tasks in the virtual environment. Further development in VR technologies such as haptic exoskeletons, haptic gloves and so on might overcome some of these problems in the future.

The VR based approach presented is meant to mainly be used in early phases of production development processes, e.g. as a complement to the more traditional way to use DHM tools on 2D computer screens. Its goal is to consider ergonomics in a proactive manner, when new workstations are designed, or existing workstations are improved.

Although DHM tools can be seen as the state of the art for the simulation of ergonomics in virtual worlds, there are aspects that typically cannot be simulated yet by the DHM approach, at least not automatically. Examples are cognitive factors such as the selection of actions. To clarify, when simulating work tasks in a DHM tool, the DHM tool user needs to define how tasks are to be performed by the manikin in the DHM simulation. This is often hard to know in detail, especially for new workstations, and it is also time consuming to enter into the DHM tool. By using the VR/mocap solution presented, the user, e.g. the simulation engineer or an operator, can rather perform the tasks in the VR world himself/herself. This can save time and enhance the correspondence with how the task is likely to be performed in the real situation. Hence, the $\mathrm{VR} /$ mocap approach brings value to DHM, and it is rather a complement than an alternative. DHM is able to consider some human aspects that would be hard to take into account with the VR/mocap approach, such as the representation of anthropometric diversity and assessment of biomechanical loads. An objective in the continuation of this research is to establish a method that allows automatic instructions of a manikin in the DHM tool, i.e. where a real human instructs the DHM manikin of what tasks that are to be simulated, where the real human is in a real or in a VR setting. 
After instructing one manikin, the other manikins in the DHM tool would perform the same tasks, possibly differently due to different constraints [40]. This would enable the simulation to represent diversity among the workforce, which is a central aspect in ergonomics.

The fact that the person testing the workstation in VR is wearing a mocap suit and VR goggles might change his/her behaviour when performing the tests in the VR world. However, advances in VR, e.g. related to realism, latency and tactile feedback, as well as in mocap technologies, e.g. related to precision, comfort and data transfer, are believed to reduce this problem in the future.

\section{Acknowledgement}

This work has been made possible with the support from the Knowledge Foundation supported research environment INFINIT at University of Skövde, in the project Synergy Virtual Ergonomics (SVE), and with support from VINNOVA in the project VIVA - the Virtual Vehicle Assembler, and by the participating organizations. This support is gratefully acknowledged.

\section{References}

[1] R. Y. Zhong, X. Xu, E. Klotz, and S. T. Newman: Intelligent Manufacturing in the Context of Industry 4.0: A Review, Engineering, vol. 3, no. 5, pp. 616-630, Oct. 2017.

[2] M. Rüßmann, M. Lorenz, P. Gerbert, M. Waldner, J. Justus, and M. Harnisch:Industry 4.0: The Future of Productivity and Growth in Manufacturing Industries, Boston Consulting Group, 9(1), 54-89., Apr. 2015.

[3] J. C. K. H. Riedel and K. S. Pawar: The consideration of production aspects during product design stages, Integr. Manuf. Syst., vol. 8, no. 4, pp. 208-214, Aug. 1997.

[4] J. A. Jose: Outcome measures and prognosis of WRMSD, Work, vol. 41, no. Supplement 1, pp. 48484849, Jan. 2012.

[5] D. A. Madani and A. Dababneh: Rapid Entire Body Assessment: A Literature Review, Am. J. Eng. Appl. Sci., vol. 9, no. 1, pp. 107-118, Jan. 2016.

[6] A.-C. Falck and M. Rosenqvist: A model for calculation of the costs of poor assembly ergonomics (part 1), Int. J. Ind. Ergon., vol. 44, no. 1, pp. 140-147, Jan. 2014.

[7] M. L. Resnick and A. Zanotti: Using ergonomics to target productivity improvements, Comput. Ind. Eng., vol. 33, no. 1, pp. 185-188, Oct. 1997.

[8] A.-C. Falck, R. Örtengren, and M. Rosenqvist: Assembly failures and action cost in relation to complexity level and assembly ergonomics in manual assembly (part 2), Int. J. Ind. Ergon., vol. 44, no. 3, pp. 455-459, May 2014.

[9] M. F. Antwi-Afari, H. Li, D. J. Edwards, E. A. Pärn, J. Seo, and A. Y. L. Wong: Biomechanical analysis of risk factors for work-related musculoskeletal disorders during repetitive lifting task in construction workers, Autom. Constr., vol. 83, pp. 41-47, Nov. 2017.

[10] Falck, A., Örtengren, R. and Högberg, D:The Impact of Poor Assembly Ergonomics on Product Quality: A Cost-Benefit Analysis in Car Manufacturing, Vol. 20, No. 1, pp. 24-41, 2010.

[11] S. B. Wong and S. Richardson: Assessment of working conditions in two different semiconductor manufacturing lines: Effective ergonomics interventions, Hum. Factors Ergon. Manuf. Serv. Ind., vol. 20, no. 5, pp. 391-407, 2010.

[12] S. Scataglini and G. Paul, DHM and Posturography. Elsevier Academic Press, 2019.

[13] S. Summerskill, R. Marshall, S. Cook, J. Lenard, and J. Richardson:The use of volumetric projections in Digital Human Modelling software for the identification of Large Goods Vehicle blind spots, Appl. Ergon., vol. 53, pp. 267-280, Mar. 2016.

[14] M. Pekar, P. Trebu, R. Popovi, and M. Kliment:Utilization of the software product tecnomatix jack in optimizing of working activities, vol. 1, no. 4, p. 7, 2015. 
[15] P. Ruiz Castro, N. Mahdavian, E. Brolin, D. Högberg, and L. Hanson: IPS IMMA for designing human- robot collaboration workstations, presented at the 5th International Digital Human Modeling Symposium, Bonn, Germany, June 26-28, 2017, 2017, pp. 263-273.

[16] K. Abdel-Malek et al.: Santos: A Digital Human in the Making, University of Iowa. Center for Computer Aided Design. 2008.

[17] G. C. David: Ergonomic methods for assessing exposure to risk factors for work-related musculoskeletal disorders, Occup. Med., vol. 55, no. 3, pp. 190-199, May 2005.

[18] [18] L. McAtamney and E. Nigel Corlett: RULA: a survey method for the investigation of workrelated upper limb disorders, Appl. Ergon., vol. 24, no. 2, pp. 91-99, Apr. 1993.

[19] L. McAtamney, S. Hignett, and S. Hignett: Rapid Entire Body Assessment, Handbook of Human Factors and Ergonomics Methods, 30-Aug-2004. [Online]. Available: https://www.taylorfrancis.com/. [Accessed: 06-Feb-2019].

[20] O. Karhu, P. Kansi, and I. Kuorinka: Correcting working postures in industry: A practical method for analysis, Appl. Ergon., vol. 8, no. 4, pp. 199-201, Dec. 1977.

[21] M. Aurbach, K. Wagner, F. Süß, and S. Dendorfer: Implementation and Validation of Human Kinematics Measured Using IMUs for Musculoskeletal Simulations by the Evaluation of Joint Reaction Forces, in CMBEBIH 2017, Singapore, 2017, pp. 205-211.

[22] N. Vignais, M. Miezal, G. Bleser, K. Mura, D. Gorecky, and F. Marin: Innovative system for real-time ergonomic feedback in industrial manufacturing, Appl. Ergon., vol. 44, no. 4, pp. 566-574, Jul. 2013.

[23] P. Zawadzki and K. Żywicki: Smart Product Design and Production Control for Effective Mass Customization in the Industry 4.0 Concept, Manag. Prod. Eng. Rev., vol. 7, no. 3, pp. 105-112, Sep. 2016.

[24] S. Aromaa and K. Väänänen: Suitability of virtual prototypes to support human factors/ergonomics evaluation during the design, Appl. Ergon., vol. 56, pp. 11-18, Sep. 2016.

[25] T. S. Mujber, T. Szecsi, and M. S. J. Hashmi: Virtual reality applications in manufacturing process simulation, J. Mater. Process. Technol., vol. 155-156, pp. 1834-1838, Nov. 2004.

[26] G. Michalos, A. Karvouniari, N. Dimitropoulos, T. Togias, and S. Makris: Workplace analysis and design using virtual reality techniques, CIRP Ann., vol. 67, no. 1, pp. 141-144, Jan. 2018.

[27] B. Daria, C. Martina, P. Alessandro, S. Fabio, V. Valentina, and I. Zennaro: Integrating mocap system and immersive reality for efficient human-centred workstation design, IFAC-Pap., vol. 51, no. 11, pp. 188-193, Jan. 2018.

[28] F. Caputo, A. Greco, E. D’Amato, I. Notaro, and S. Spada: A Preventive Ergonomic Approach Based on Virtual and Immersive Reality, pp. 3-15 In International Conference on Applied Human Factors and Ergonomics (pp. 3-15) July 2017,

[29] M. Peruzzini, S. Carassai, and M. Pellicciari: The Benefits of Human-centred Design in Industrial Practices: Re-design of Workstations in Pipe Industry, Procedia Manuf., vol. 11, pp. 1247-1254, Jan. 2017.

[30] J. Eklund and M. Forsman: Smart work clothes give better health - Through improved work technique, work organization and production technology, presented at the 20th Congress of the International Ergonomics Association, IEA 2018, Florence, Italy, 26 August 2018 through 30 August 2018, 2019, vol. 820 , pp. $515-519$.

[31] N. Mahdavian et al.: Effect of Giving Feedback on Postural Working Techniques, presented at the 16th International Conference on Manufacturing Research, incorporating the 33rd National Conference on Manufacturing Research, September 11-13, 2018, University of Skövde, Sweden, 2018, pp. 247-252.

[32] C. M. Lind et al.: Prevention of Work-Related Musculoskeletal Disorders Using Smart Workwear The Smart Workwear Consortium, presented at the IHSED 2018: Human Systems Engineering and Design, Champagne-Ardenne, October 25-27, 2018., 2019, vol. 876, pp. 477-483.

[33] A. Iriondo, D. Högberg, A. Kolbeinsson, P. Castro, N. Mahdavian, and L. Hanson: Proposal of an Intuitive Interface Structure for Ergonomics Evaluation Software: Volume VIII: Ergonomics and Human Factors in Manufacturing, Agriculture, Building and Construction, Sustainable Development and Mining, 2019, pp. 289-300.

[34] Vive, VIVETM |Discover Virtual Reality. Accessed: 21.10.2019. [Online]. Available: https://www.vive.com/eu/

[35] M. Suznjevic, M. Mandurov, and M. Matijasevic: Performance and QoE assessment of HTC Vive and Oculus Rift for pick-and-place tasks in VR, in 2017 Ninth International Conference on Quality of Multimedia Experience (QoMEX), 2017, pp. 1-3.

[36] Industrial Path Solutions, IPS | Industrial Path Solutions (IPS). Accessed 19.10.2019. [Online]. Available: https://industrialpathsolutions.se/

[37] N. Ewalt, Hotrian/OpenVRDesktopDisplayPortal. 2019.

[38] I. Arvidsson, C. Dahlqvist, H. Enquist, T. Dr, and C. Nordander: Åtgärdsnivåer mot belastningsskada, Occupational and Environmental Medicine Syd's report 2017. 
[39] C. M. Lind: Assessment and design of industrial manual handling to reduce physical ergonomics hazards - use and development of assessment tools - Semantic Scholar, KTH, Stockholm, SWE, Dissertation, 2017.

[40] E. Billing, L. Hanson, M. Lamb, and D. Högberg: Digital Human Modelling in Action, presented at the SweCog 2019, the 15th SweCog conference, Umeå, Sweden, November 7-8 ,2019, pp. 25-28 